\title{
Telecare technologies and isolation: some ethical issues
}

This article was published in the following Dove Press journal:

Smart Homecare Technology and TeleHealth

5 May 2015

Number of times this article has been viewed

\section{Andrew Eccles}

School of Social Work \& Social Policy, University of Strathclyde, Glasgow, UK

Video abstract

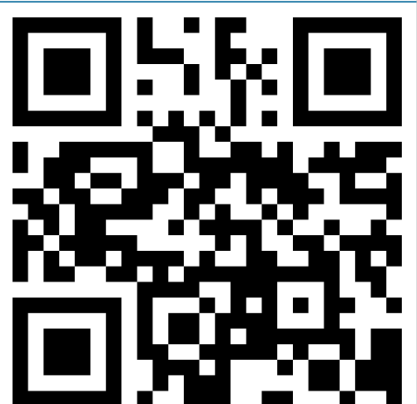

Point your SmartPhone at the code above. If you have a $Q R$ code reader the video abstract will appear. Or use: http://youtu.be/s0nDFxabR2
Correspondence: Andrew Eccles

School of Social Work \& Social Policy, Lord Hope Building, University of Strathclyde, Cathedral Street, Glasgow G4 OLT, UK

Email andrew.eccles@strath.ac.uk
Abstract: Telecare technologies involve the remote monitoring of patients who have health, rehabilitation or social needs. These technologies, although deployed unevenly in developed countries, represent a shift in the ways in which care is practiced. Research on the consequences of this shift away from more traditional "hands-on" care has focused primarily on quantitative measurement (for example cost savings) with less attention paid to how recipients themselves experience these new care practices. This paper discusses two aspects of telecare technologies which are under researched; the potential for loneliness which may arise as a result of the use of these technologies, and the ethical issues raised by this. The primary locus of the discussion is the UK, where a major public policy shift towards telecare is under way and where telecare research based on randomized control trials has been particularly well funded by the government. The discussion concludes that there is indeed the potential for loneliness, a condition increasingly recognized as a significant factor in reducing overall health and well-being, in the use of these technologies. The ethical implications of this are not being sufficiently considered, in part because the ethical frameworks in use do not adequately address the issue of loneliness itself, given their bio-medical, rather than relational focus. The paper suggests two ways of redressing this. First, the addition of approaches to ethics other than bio-medical - particularly those with a relational and contextual focus - or greater exploration of how the two approaches might interact. Second, it suggests that a paradigm shift towards solutions other than technology-based care is overdue. This shift would not underplay the importance of technological contributions to care needs. It would, however, be an argument to suggest we proceed with some caution, advance the research evidence on the complexity of users' experiences of these technologies, and explore potentially simpler - and ethically more relational - approaches to care, such as shared or intergenerational living.

Keywords: telecare, isolation, loneliness, ethics, public policy

\section{Introduction}

Telecare technologies have come to the fore in health and social care in recent years. These technologies are designed to allow their recipients to remain in their own homes through the deployment of technological solutions to care needs that involve remote monitoring and response. Different "generations" of telecare technologies have seen increasingly more sophisticated applications; from simple alarms to activity sensors and GPS-based tracking devices. Recipients span age groups, but are most likely to be older people, often with a degree of disability or vulnerability.

The deployment of telecare technologies has been the subject of discussion and debate, from which three broad areas stand out. First, these technologies are increasingly replacing, rather than just supplementing, human care. This is not axiomatically 
problematic and indeed such replacement may be cost effective and lead to effective intervention. ${ }^{1}$ However these new forms of care - in which the care relations are mediated in different ways - are often more complex than the discourses of technologists might suggest and are under-researched. ${ }^{2}$ Second, there is dispute over the efficacy and cost effectiveness of these technologies. This is in part because of the methodological difficulties which attend research and evaluation in such a complex area. The largest evaluation of telecare and telehealth, in world terms, has been in the United Kingdom (UK), with the Whole System Demonstrator (WSD) project, based on randomized control trials involving 6191 patients and 238 General Practitioner practices and funded by the UK government at approximately $£ 31$ million (US\$51 million). The results of these evaluations ${ }^{3,4}$ have challenged the dominant discourse to date in UK policy circles, which has emphasized significant cost savings and enhanced quality of life, ${ }^{5}$ by concluding that broad arguments for either of these aspects are not well founded. As the Parliamentary Office of Science and Technology reported, "The results of the [WSD] telecare $[\ldots]$ showed no statistically significant reduction in health or social care use between the telecare and non-telecare groups" and further recorded: "The results of the telehealth economic evaluation [...] showed that telehealth was not cost-effective at the scale implemented in the trial". ${ }^{6}$ Third, these technologies, based, as they increasingly are, on surveillance (for example through monitoring of conditions or GPS tracking of movements) - and in the new care relations they presage - prompt ethical issues hitherto unexplored. Thus, concern has been voiced here about what Mort et al have argued is an "ethical and democratic deficit in this field which has arisen due to a proliferation in research and development of advanced care technologies that has not been accompanied by sufficient consideration of their social context". ${ }^{\text {? }}$

It is this element - the ethical angle - which will be considered here. Literature specifically on ethical issues and the deployment of telecare technologies has been limited in scale but also, for the most part, in scope, covering the key territory from bio-medical ethics; questions of autonomy, risk, potential harm, and the just distribution of goods. ${ }^{8-10} \mathrm{An}$ even smaller field of enquiry has explored ethical approaches beyond the bio-medical domain - for example an ethic of care and virtue ethics. ${ }^{11,12}$ What has not been discussed in the literature are the particular ethical issues which might emerge from a further potential element of telecare use; that is, isolation, and the potential this brings for the condition of loneliness. The issue of the potential for loneliness in telecare deployment itself has been discussed ${ }^{13}$ and notes that where loneliness leads to depression we are faced with an issue of well-being which is less easy to detect and, if detected, tends to be accorded a relatively low priority in the field of medicine compared to, for example, more acute conditions. As is discussed in the Background section, the association of loneliness with health and well-being is increasingly acknowledged to be wider than just mental health. We thus have an interesting issue at hand; that is, telecare technologies are being deployed on the grounds of cost effectiveness and enhanced quality of life ${ }^{5,14}$ but these same technologies have the potential to increase loneliness, an issue now acknowledged to have a very significant association with deficits in health and quality of life. This paper explores some of the ethical issues raised by this.

\section{Background}

Some 30 years ago, in Exploring Medical Ethics, Henlee Barnette ${ }^{15}$ devoted a chapter to the ethics of loneliness. This was unusual, as the issue of loneliness rarely found itself in discussion around ethics. Nor, indeed, as Barnette pointed out, was it the subject of enquiry more generally in medical textbooks, with minimal representation in the key texts of the time. Indeed, despite its title - the ethics of loneliness - the Barnette discussion actually centers more on the causes and symptoms of loneliness than on ethical issues per se, but alights on areas with an ethical dimension, such as obligation and distribution of goods. The likely reason for this lack of research into loneliness and its attendant ethical aspects is the lack of precision with which the term loneliness could be described or attributed; it will mean, perceptually, different things to different people. This then alights on a key point at the outset of the discussion here, viz the lack of clarity with which we are able to talk of loneliness. There are selfreporting devices which measure loneliness but these offer essentially quantitative accounts, represented as they usually are on scalable measures. Thus more accurately we should talk of felt loneliness; that is, the phenomenon as experienced by an individual which cannot be understood without the more contextual reference afforded by qualitative inquiry. This may explain also the reticence with which loneliness has historically been recognized as a medical category; since it lacks objective measure, it is by definition harder to treat. It is this notion of felt loneliness that underpins the use of the term loneliness in this paper.

Things have changed; for example, there is now a much more substantial literature on loneliness and awareness in policy circles of the condition. Undoubtedly the latter interest has been spurred by a series of papers in recent years 
alighting on an association between loneliness and significant aspects of ill health. ${ }^{16,17}$ In addition to an increased incidence of illness centered on cardiovascular risk and depression, ${ }^{18}$ loneliness has also been linked to a significant increase in the likelihood of dementia. ${ }^{19}$ These are associations; correlations are harder to make given the variables involved, but we now have a clearer understanding of what would appear to be a significant nexus between loneliness and a range of morbidities; from research that is wide ranging, cross cultural, and longitudinal. This means that loneliness is now more firmly in the domain of health considerations, while its potential for adverse impact on health has also alerted policy makers to the attendant extra financial costs in health care. Two caveats might be useful here. First, while the evidence for an association between loneliness and broader conditions of ill health is not openly disputed, we still need to understand more precisely the connection that links them. Second, there remain aspects of definition which may need clarification. Thus loneliness should not be confused with social isolation. There may be many people living in the latter circumstance who would not class themselves as lonely and who, indeed, may find positive attributes in such isolation; social isolation is not in itself necessarily problematic. There are ways of classifying the distinction between loneliness and social isolation; but these tend to be based on self-reporting, which, as a method of recording, may be quantitatively exact but qualitatively open to interpretation. People's understanding of scales or categories might not be the same and this can lead to interesting results, such as the prevalence of higher than average recordings of quality of life by people who have disabilities which might be expected to impact on selfrecorded scores. ${ }^{20} \mathrm{~A}$ parallel problem can be found in quality of life recording and exploring links between telecare and better quality of life (which is cited by technology companies and governments alike as an outcome of its deployment). To make such a direct claim is questionable; there may be indicators of quality of life which can be facilitated by telecare technologies, but such are the variables here that claims of a direct correlation are best avoided..$^{21}$ In practice terms this is a distinction which may require a nuanced understanding of what constitutes loneliness for individuals which may not always be afforded by the time set aside for an assessment of telecare deployment. The replacement, by monitoring equipment, of care workers whose role, inter alia, was to check-in with vulnerable people in their own homes has been resisted by some clients. What then, if the care worker service is no longer available? Should monitoring equipment be installed regardless, on the grounds that this is the only service available given cost constraints? As has been noted, ${ }^{21}$ there are instances where telecare was the only option available to people in their own homes, with institutional care the only alternative. We thus have a number of complexities here, from which three key issues emerge. First, there is substantial evidence of a link between loneliness and wider ill-health. But this link will not be predictable for everybody in the same way, and our understanding of what constitutes loneliness in individual cases will not lend itself to standardized solutions. How we deal with social isolation compounds the difficulty; while people who are socially isolated are not necessarily lonely, they may still warrant, from a practitioners' point of view, a degree of safeguarding; for example via remote monitoring. Second, telecare technologies themselves tend to be standardized, a product of manufacturing economies of scale. Where different technologies might constitute a useful package of care, there may remain issues of inoperability across technologies, a phenomenon all too prevalent but which the industry as a whole has been slow to address. As Greenhalgh et al, ${ }^{2}$ have highlighted, overcoming this standardization through the individual personalization of these products may be possible, but only to a limited extent. These are active debates; procurement policies, the limits to post installation "tinkering" of technologies, the adequacy of explanation with end users of the technologies' purpose and subsequent review of their utility have been discussed at length by the author with telecare practitioners. ${ }^{22,23}$ Third, the very telecare technologies which can offer "peace of mind" for family members of the recipients of these technologies (for example vulnerable older people) can also lead to greater isolation of these very recipients. If family members are content that their vulnerable relations are connected via an alarm system or are being monitored they may feel less inclined to interact in person. This may be of enormous benefit to family members who may have their own commitments (for example, work) and care obligations (for example, children), especially in an era of greater social and geographic mobility. Again, there are nuances here; carers may be able to commit to a greater degree of quality of time with family members who have telecare devices on occasions when they do visit but there are no easy predictors to this. ${ }^{24}$ What emerges from these studies is also the broader point of a need to develop and sustain more qualitative research into users' experiences of telecare technologies.

\section{Loneliness and public policy}

Two further aspects compound the problem of loneliness as a policy issue; first, loneliness is particularly prevalent amongst 
older adults, whose demographic has been the subject of much policy concern over the past 30 years, particularly in relation to the "dependency ratio" 25 between older people and an available labor supply to fund care costs and deliver care itself. Second, this loneliness amongst older adults is at the center of something approaching a "perfect storm" in policy terms; the fiscal stress in funding for health and social care across the developed world, in societies which have altered radically in the same 30 year period to become more fragmented, less cohesive and with fewer reserves of community based social capital. Into this perfect storm has come a potential solution in policy terms - indeed, a solution viewed in the UK by the Audit Commission, ${ }^{26}$ guardian of the public finances, as a potential "win/win" scenario of better care which is also cheaper - that is, technology-based care, especially in the form of information and communication technologies (ICT). Nonetheless, this technology-based approach has been embraced unevenly in developed countries; interestingly, given the Audit Commission antecedents, it is in the UK that its growth has been most significant and projected use most ambitious. The United States, ${ }^{27}$ Nordic countries, ${ }^{28}$ and the Netherlands ${ }^{29}$ are also to the fore in research, development, and deployment of these technologies; otherwise the pattern is inconsistent, despite similar demographic trends across the developed world.$^{30}$ Different types of technology engagement from ICT approaches are also being developed apace, for example in Japan; these are less based on information and communication but more on physical representations of technology such as robotics and are rooted in a strong bias towards active aging and community based health care. ${ }^{31}$

Two issues emerge from these developments. First, there is evidence of the institutions of government - for example the European Commission - emerging effectively as "cheerleaders" for technology-based solutions to care needs, despite conflicting evidence around its efficacy. ${ }^{32} \mathrm{This}$ is particularly the case in the UK, leading to the admonishment by Pols and Willems that:

The dubious status of promises and the unpredictable processes of domestication [of technologies] that are so hard to trap with standard research methods, make implementing telecare technologies on a large scale and on a top-down basis, as is done in the UK, a hazardous investment. ${ }^{33}$

Second, there has been limited attention paid, particularly amongst policy makers, to ethical issues arising from the use of these technologies. Where ethical issues are discussed, it is usually on the basis of a highly reductionist bio-medical approach, which may have particular relevance in informing decision making in settings of acute medicine but has less utility in guiding approaches to resolving tensions in longterm care. As a result, the issue of loneliness - while now acknowledged as a significant factor in morbidity, especially amongst older people - has been under-researched in ICT outcomes (in which qualitative research remains underfunded and still questioned, in terms of validity, in relation to standardized trials around usage and costs). It also remains off the radar in ethical terms, as the kind of issues which might be explored in an ethics of loneliness are more likely to be located in approaches other than those which are bio-medical in underpinning; approaches drawn from an ethics of care, intuitional ethics or virtue ethics.

\section{Ethical issues}

Perhaps the first ethical issue to consider is the scope of ethical enquiry itself. Beauchamp and Childress' (2012) Principles of Biomedical Ethics now runs to a seventh edition. ${ }^{34}$ Here we find exploration based on familiar approaches from the medical field: autonomy, beneficence, non-maleficence, and justice. These - principalist - concerns are, rightly, crucial areas of enquiry. They are essentially rule based (in the sense there is a baseline to appeal to in formulating ethical responses); although the outcomes of the application of these rules are nonetheless open to interpretation. Non-maleficence (do no harm), for example, seems self-evident but has to be considered in terms of proportionality. Thus we may find it acceptable to encounter some harm to prevent wider harm (a procedure such as invasive surgery) or indeed future good. This will involve some calculus. The same can be argued about questions of justice, which may center on the distribution of goods (who should get treatment, given competing demands, finite resources, and future life chances). Autonomy plays a powerful part in such considerations; as Wilmot ${ }^{35}$ notes, the "primacy of autonomy" is a central feature of the enlightenment tradition which persists in modern health and social care, and which places particular emphasis on the rights of the individual to shape their own lives and consent to procedures that impact upon them; this despite the obvious inter-dependency inherent in much of health and social care, where, for example, facilitating independence through monitoring technologies will still require monitored data to be collated, filtered and, if need be, acted upon.

These bio-medical categories transpire to be the central features of ethical frameworks widely in use in the field of telecare; it would be interesting to explore how these were adopted; it seems most likely by default, in the sense these 
frameworks are known and readily available (for example the Care Services Improvement Partnership in the UK). ${ }^{36}$ But here we have a problem. In a similar vein to how loneliness has only relatively recently become a more important issue in health care, based on substantive studies linking it to long standing morbidities, we have a historic deficit in our understanding of ethical issues connected to loneliness. This is in part because the elements which constitute loneliness are so varied, and subject to individual lived experience, that it is difficult to have them the subject of rule-based frameworks. Thus the frameworks for both ethical enquiry in telecare and a wider discussion around an ethics of loneliness which tend to be employed by policy makers are of limited use, because they are dealing with complexities that are ill-served by the rather reductionist approaches they adopt. These ethical debates have evolved, however, to embrace the complexities which emerge from assistive technologies. One such example can be found around the issue of self-determination; as Nagel and Remmers ${ }^{37}$ argue:

$[\ldots]$ one cannot assume the distanced, judgmental perspective on attitudes and moral relations that is usually claimed for external artifacts, [... when ...] human intentionality as a basis for self-determination is merged with technological intentionality

meaning, as the authors further note, "[...] humantechnology immersion might change who is the originator of self-determination by changing how users of technology perceive themselves". Thus the issue here is the need to explore the complexities of people's engagement with telecare technologies; to connect assumptions about technical potential with the phenomenology of lived experience. An appreciation of this lived experience of technology users might also be illuminated by a reframing of ethical approach, going beyond the bio-medical framework to the field of relation ethics; an approach which may in itself better engage with the issue of loneliness.

\section{Relational approaches in ethics}

An ethic of care has emerged as part of wider debates in ethics in the past 30 years, following on from the pioneering work in difference feminism of Gilligan ${ }^{38}$ to be progressed and adapted by writers such as Noddings, ${ }^{39}$ Tronto, ${ }^{40}$ and Held. ${ }^{41}$ Later editions of the Beauchamp and Childress text Bio-medical Ethics ${ }^{34}$ have a chapter dedicated to an ethic of care and thus it is present (if not necessarily discussed and utilized) in mainstream ethical debate in medicine. Whilst not uniform in their arguments, there are common themes underpinning these authors on an ethic of care. These center around the importance of relationships; across those being cared for and those caring, albeit the issue of the term care is itself the subject of some debate, with the argument that the notion of care may unacceptably limit recipients' selfdetermination. ${ }^{42,43}$ Thus central to how we proceed will be decisions which are relational between care giver and care receiver and not derived from abstract categorizations. Indeed care is often actually reciprocal between givers and receivers, and not merely contractual. ${ }^{43}$ This in itself may impact on the willingness of carers to embrace new telecare technologies, as carers' own identities may be bound up in the caring roles they play. In this sense recipients of care may be adversely affected by not being exposed to the beneficence (often characterized as independence) that such technologies might bring.

An ethic of care will be prompted also by a disposition to care, based on competence and attentiveness to the tasks in hand. ${ }^{40}$ What this means in practice is that whilst more readily acknowledged ethical approaches would stress the importance of autonomy, an ethic of care starts with an acknowledgment of how fundamentally interdependent we are; none of us is fully independent, indeed the infrastructure to allow us to have a nominal independence is often tacit; we all need help and support to some degree, often in subtle ways which may be readily unexamined in everyday discourses. ${ }^{44}$ This may also explain the different approaches, despite similar demographic trends, to technology-based care in Asia, where the limits to autonomy are culturally shaped by a stronger tradition of interdependence and community connectedness. ${ }^{45}$

If we then look at telecare technologies through an ethic of care lens, what issues present themselves? First, the nature of the relationships is altered. Instead of traditional human relations, we have relationships at a remove; the triaging of responses by operatives in a call center takes the place of, for example, a "home visit" by a health or social care professional. Second, not just the notion of independence but its reality becomes further reinforced because telecare users and operatives are physically separate in a world of telecare technologies. Third, the disposition to care is brought into relief; what is the professional background, training, and attendant value bases of call center operatives who triage decision making as telecare responders? These same questions can be posed about assessments for the installation of telecare technologies in the first instance; what is the ethical code and value base of these assessors, given we know they may have different educational and professional backgrounds? Since many recipients of these technologies will have some 
degree of disability, which model of disability framing will be employed; medical or social?

There are complexities here that warrant some further comment. The notion that there is a dichotomy between "warm care and cold technology" has been explored and convincingly rebutted. ${ }^{46}$ These are not components at either end of a care continuum. Pols' work ${ }^{1}$ on people living in remote areas of the Netherlands notes the way in which service users (in this case people who had cancer) would respond with what amounted to some affection to prompts from the technology installed in their homes but who may have found direct contact with health practitioners more foreboding or embarrassing. Similarly, Oudshoorn's research $^{29}$ on the dynamics of telecare heart-monitoring call centers sheds light on the practices of care in these settings, where relationships, albeit remote, were often developed between users and operatives. That said, Oudshoorn's work also examines the phenomenon of non-users of these monitoring technologies; people who are readily classed in the discourse of technologists as "technophobes". Enquiry here discovered that these people were often anything but technophobes; they were educated, articulate, and technologically adept. Their resistance to these specific telecare technologies was based on their use in this specific care practice; so, although technologically literate, these recipients expressed a preference for human relationships in this particular aspect of their lives. This notion of competing discourses around technology use is explored further in the literature. Greenhalgh et $\mathrm{al}^{47}$ in reviewing the discourses of technologists, service managers and service users highlight the different terminologies and interpretations of language across different groupings, which means that the issues arising from their use may not enter the realm of having an ethical dimension amongst some parties. Kamphof ${ }^{48}$ has explored the interaction between practitioners and service users in the remote monitoring of health conditions, where the gathering and interpretation of data alters traditionally understood care practices. These new responsibilities for "care at a distance" practitioners hint at the potential for an occupational loneliness; a condition which may also be experienced by clinicians who, in taking advantage of the efficiencies afforded by remote monitoring technologies, observe only specific aspects of their patients, disembodied from the patient themselves without recourse to the usual human interactions that might surround a hospital consultation. Of course, these aspects of changes to care practices can be overstated: not all medical consultants are necessarily patient-friendly, while the savings in the costs and inconvenience of travel to a hospital consultation for the remotely monitored patient need to be factored into the equation here. Telecare call centers, as a way of working, may also fit this tension; where there was social interaction in home visits there is now a more atomized working practice which entails a more procedural reading from a script and clear guidelines on how to proceed. But there is a danger here of romanticizing more traditional patterns of home care. Whilst the evidence is variable, the experience of homecare services in, for example, the UK points to increasingly time constrained, highly functional (the completion of tasks rather than attentive care), and often impersonal, low paid carers. ${ }^{49}$ The reality of care practice is that telecare technologies may offer more reliable and attentive care compared to human care under the current conditions of home care practices. Here, the mantra of autonomy and independence which underpins much of the telecare discourse has its flip-side; the increasingly atomized, contractual, impersonal relations that characterize the working conditions of paid carers (see Tronto $^{44}$ for a fuller discussion). Indeed, there is concrete evidence about these understandings of care and care needs from the study of decision making in telecare operations that reveals the potential for loneliness. As part of the findings of the EFORTT project Mort et al ${ }^{50}$ note the conversations of telecare management in relation to appropriate use of telecare. This takes us again to the different discourses that make up discussions around these technologies. Mort et al note the prevalence of monitoring devices - for example, alarms that alert a call center if an entry door to a dwelling has been opened - to be used for primarily social purposes, where, for example a door alarm will be activated - perhaps without deliberation - in order to elicit a response from a call center and engage in conversation. The authors observed how this use of the technology was deemed "inappropriate" by telecare operational managers, in the sense that it was not being used for the purpose intended at the time of its installation. These discussions then centered on whether or not the alarm technology should be removed from the recipients given that the "inappropriate" use entailed costs of using call center staff time. Here the difficulties lie with the different discourses around usefulness: for the recipients of the technology the devices provided access to conversation and thus clearly offered not only a degree of beneficence, but - albeit minimal and remotely engaged - some degree of relational care. Some telecare projects explicitly recommend the development of a network of befrienders in anticipation that technological solutions to care-needs could leave their recipients isolated. But this laudable concept has to be 
tempered in the reality of an era in which social capital is under stress and traditional ties in communities loosened.

Thus far we have considered some ethical questions which attend the implementation of, for the most part "second generation" telecare, based on monitoring and remote care technologies. As technologies advance in this field, so the ethical issues are reshaped. The potential for feelings of loneliness which may attend settings where people who are subject to monitoring technologies but nonetheless socially isolated, can be alleviated by the liberating impact of "third generation" telecare based on GPS tracking technologies. These can facilitate a greater freedom of movement amongst, for example, people with dementia who are apt to wander (or walk, in less judgmental terminology). Here the research evidence offers clear advantages for the recipient; retention of their independence, the beneficence afforded by the health gains of remaining active, and increased opportunities for social interaction. These technologies then appear to bridge the gap between the retention of independence, as understood by people being able to remain in their own homes, and the onset of social isolation precisely because of this independent status. However the picture is more complex. Moser's ${ }^{51}$ work on older people with dementia gives us a more accurate representation of what this independence through tracking technologies entails; viz concerns on the part of significant others (often themselves older and perhaps with care needs of their own) who have responsibility for ensuring the GPS devices are fully functioning. Here the problems are prosaic, but intrinsic to the design of the technology; batteries that need to be replaced, cable leads that can be pulled out by curious wearers and a network in place to be able to respond to a recipient's recovery should the technology fail to work or the recipient fail to return as expected. Moser's research suggests these issues bring a degree of emotional stress that, again, point to a much higher degree of interdependence than the independent rubric might allow. It is here also that the issue of privacy comes to the fore; while the trade-off between privacy and security might seem particularly advantageous in this situation of using GPS tracking (albeit the technology itself is based on equipment used to track offenders who are the subject of community-based punishment in the criminal justice system), this trade-off becomes more complex in home-based monitoring which uses, for example, passive infra-red beam or sensor-based technologies. The issue here is the extent to which the loss of privacy is justified by the potential safety afforded by the technologies. The complexities of the privacy/safety debate have been well rehearsed (see Macnish, 2012 for a useful overview and discussion) $)^{52}$ and we might note that it is a false dichotomy to assume the concepts are necessarily oppositional; it is not a zero-sum game between the two, but instead involves trade-offs which are contextually located..$^{53}$ One such context might be the desirability of institutional care, with its significantly compromised aspects of privacy, as the only available alternative to monitoring of people in their own homes, given constraints on resources. But there are also ethical issues raised by the potential for behavior modification on the part of recipients in anticipation of outcomes. ${ }^{9}$ Thus, wearers of fall-detectors may adjust their behavior in order not to appear to be vulnerable should the detector be triggered. This adjustment would involve taking less risk (thus alleviating the potential for triggering the device); but this may also mean foregoing a degree of physical activity. The unintended consequences here are clear; the fall detector becomes a potentially restrictive technology which may additionally curtail the strength, stamina, and mental well-being afforded by keeping physically active. Lowe ${ }^{13}$ takes this further to ask how we would know if telecare recipients might be suffering from isolation and the attendant depression which may arise from this. The indicators here are not obvious: there may be cultural and generational responses to remote enquiry (for example, in the replacement of traditional morning visits by care staff with a remote telephone call). Recipients may understate difficulties they may be experiencing in these strictly time limited calls, where humanly present care may "pick up" on non-verbal cues about a service user's well-being.

\section{An ethic of justice}

This paper has so far discussed various aspects of ethical concern in relation to telecare, loneliness, and the individual, albeit that individuals remain essentially interdependent rather than independent. But a broader ethical issue relates to an ethic of justice; in this case, consideration of the distribution of goods. This raises the specter of the "digital divide" 54 in which different sections of the population engage at different levels and with different enthusiasm. One aspect of telecare technologies is that of ICT designed to connect people. Here the distribution of participants is uneven. This is in part an issue of engagement by age group (with older people more likely to be less engaged overall), but it would be simplistic to assume, for example, that all older people are de facto less engaged. Within older people as a category are people who see, and use, the potential of ICT regularly. A more pertinent divide would be around income (or, at the risk of introducing a more disputable category, social class). Here, again, the picture is nuanced by exceptions. There is 
evidence $^{24}$ of people on lower incomes moving away from landline-based telephones towards mobile systems which may not be compatible with some aspects of landline-based telecare technologies. This will change; GPS based technologies will address some of these incompatibilities but there will an inevitable implementation lag. However there is evidence of differential engagement by age and social class; the detail here is an issue for another paper, but one case study may suffice to illustrate the point. Research for Across the Divide (CarnegieUK Trust) ${ }^{55}$ highlights that, while 56\% of households in Great Britain in social class DE (the class most likely to be on low incomes or not in employment) have taken up fixed broadband, in the city of Glasgow - notable for its areas of substantial poverty - the figure is only $36 \%$. The figures become even more differentiated when comparing for age, regardless of social class; for the 65 and over population $43 \%$ for the UK and $12 \%$ for Glasgow. Glasgow is the largest conurbation in Scotland and an area of striking health inequalities. The Scottish Government itself, meanwhile, has embarked on a particularly ambitious program of telecare and telehealth, positioning itself as a world leader in this field. Of course broadband in itself is not a required technology for telecare and telehealth, given the information being relayed. But what the figures are indicative of, are the socio-economic and age-related divisions more generally around the issue of ICT technologies. It is these populations - social class DE and, by age, people over 65 , who most likely fit the profile for potential solutions in, for example, chronic obstructive pulmonary disease rehabilitation and care offered by telecare and telehealth technologies - and yet who are least engaged with communication technologies. There is thus potentially a considerable task involved in making recipients of these technologies comfortable with their use, not only in terms of rehabilitation, but in overcoming policy assumptions about the potential for connectedness. Other populations may have greater familiarity with the potential of these technologies and also be better able to articulate their demands to policy implementers, whether primarily invested in by the State (as in the UK) or private health and care providers. There needs to be recognition, therefore, that the ethical issue of a just distribution of goods comes to the fore here.

\section{An alternative approach to the question of care?}

Perhaps we would, by way of conclusion, be better served by a paradigm-shifting view of how loneliness and telecare interact. Thus, in its celebration of promoting independence, telecare offers a technological "fix" designed to continue current patterns of care, with their emphasis on maintaining people in their own homes. Of course this independence is compromised by the challenge to independence posed by monitoring and tracking technologies, an area which would merit more critical consideration. Instead of these technological fixes to dominant understandings of what it is that people value, it may be more useful to rethink care relations. ${ }^{27}$ So, for example, Germany - despite its population size, budgetary commitments, and ratio of older people - has singularly not adopted government-led telecare technology solutions to care delivery in the manner of the UK. The trend in Germany - sponsored by the federal government - is the growth of shared housing, especially between older people and a younger generation based on reciprocity of interests; companionship for the former, affordable accommodation for the latter. The symbiosis here has particular potential in large urban areas, where there may be a less clearly defined sense of local community to support older people and where availability of employment attracts, and the incidence of high housing costs impacts upon a younger generation. This policy extends also to intergenerational thinking across sites involving degrees of institutional restriction - for example the physical juxtaposition of kindergartens and day care sites for older people. Of course such developments are, to a greater or lesser extent, culturally specific and thus not necessarily transferable; Germany, for example, has long had a history of cooperative housing movements. Nonetheless there are similarities; the two countries have the lowest proportion of citizens in the European Union who feel close to people in their local area ${ }^{56}$ and thus bears scrutiny as a policy initiative; indeed, as was remarked in a discussion forum about the WSD telecare research in the UK, the $£ 31$ million (US\$51 million) spent on the research could have contributed to funding collective neighborhood solutions to the problems of meeting care needs and isolation. ${ }^{27}$ There is now some appreciation of this approach in policy thinking in the UK. ${ }^{57,58}$ But there are conceptual challenges. As Fox ${ }^{59}$ points out, in relation to public policy in the UK: "The German model challenges accepted notions of risk, with risks that terrify organisations given far more prominence over risks - such as loneliness that terrify people". This is asking difficult questions of the managerialist, risk-averse, culture which has come to permeate much of health and social care policy implementation in the UK in recent years. ${ }^{60}$ Home ownership in the UK has also been heavily promoted by the State in recent years, ${ }^{61}$ as a consequence of which ownership became markedly higher in the UK than in comparator welfare state economies and has come to be seen by householders as a crucial form of 
financial investment, in part due to its potential for equity release in later life. These factors would make a paradigm shift to new forms of shared living more problematic. But circumstances are changing. The prevailing growth area is now rented property, given the unaffordability of first-time housing costs and depressed income levels, and so an era that defined the UK - that of a "property owning democracy" - is increasingly passé. Thus the ground for some radical thinking on these issues of how we care in future is more fertile than might be assumed. In its way lie two discourses to be negotiated; governments still wedded to a particular model of community care (the individual in his or her home backed by technologies which ostensibly enhance independence) and technology companies looking for predictable markets in which to expand.

This alternative way of thinking about the issue of loneliness and how it might be addressed is in no sense an argument for underplaying the importance of technological solutions to care needs and to utilizing their potential to deliver cost effective care. To ignore its current role and remarkable potential is neither realistic nor warranted. It is, however, an argument to suggest we proceed with some caution, respect the research evidence on the complexity of users' experiences of these technologies, and perhaps think more "out of the box" to explore potentially simpler - and ethically more relational - approaches to the questions raised in this field.

\section{Disclosure}

The author has no conflicts of interest to disclose.

\section{References}

1. Pols J. Care at a Distance. Amsterdam: Amsterdam University Press; 2012.

2. Greenhalgh T, Wherton J, Sugarhood P, Hinder S, Procter R, Stones R. What matters to older people with assisted living needs? A phenomenological analysis of the use and non-use of telehealth and telecare. Soc Sci Med. 2013;93:86-94.

3. Cartwright M, Hirani S, Rixon L, et al. Effect of telehealth on quality of life and psychological outcomes over 12 months (Whole Systems Demonstrator telehealth questionnaire study): Nested study of patient reported outcomes in a pragmatic, cluster randomised control trial. BMJ. 2013;346:f653.

4. Greenhalgh T. Whole System Demonstrator trial: policy, politics, and publication ethics. BMJ. 2012;345:e5280.

5. Department of Health. Improving quality of life for people with long term conditions. [webpage on the Internet]. GOV.UK; 2013 [cited March 25, 2013] Available from: https://www.gov.uk/government/policies/improving-qualityof-life-for-people-with-long-term-conditions. Accessed July 15, 2014.

6. Parliamentary Office of Science and Technology. Telehealth and Telecare. Paper no 456. London: POST; 2014.

7. Mort M, Roberts C, Milligan C. Ageing, technology and the home: A critical project. European Journal of Disability Research. 2009;3(2): 85-89.

8. Bouma H. Professional ethics in gerontechnology: A pragmatic approach. Gerontechnology. 2010;9(4):429-432.
9. Ganyo M, Dunn M, Hope T. Ethical issues in the use of fall detectors. Ageing and Society. 2011;31(8):1350-1367.

10. Ratto M. Ethics of seamless infrastructures: Resources and future directions. International Review of Information Ethics. 2007;8(12): 21-27.

11. Eccles A. Ethical considerations around the implementation of telecare technologies. Journal of Technology in Human Services. 2010;28(1-2):44-59.

12. Perry J, Beyer S, Holm S. Assistive technology, telecare and people with intellectual disabilities: ethical considerations. J Med Ethics. 2009;35(2):81-86.

13. Lowe C. Beyond telecare: The future of independent living. Journal of Assistive Technologies. 2009;3(1):21-23.

14. Scottish Government. A National Telehealth and Telecare Delivery Plan for Scotland to 2015: Driving Improvement, Integration and Innovation. Scotland: Scottish Government; 2012. Available from: http://www. scotland.gov.uk/resource/0041/00411586.pdf. Accessed October 29, 2014.

15. Barnette H. Exploring Medical Ethics. Macon, Georgia: Mercer University Press; 1982.

16. Alspach JG. Loneliness and social isolation: Risk factors long overdue for surveillance. Crit Care Nurse. 2013;33(6):8-13.

17. Steptoe A, Shankar A, Demakalos P, Wardle J. Social isolation, loneliness and all-cause mortality in older men and women. Proc Natl Acad Sci. 2013;110(15):5797-5801.

18. Hawkley L, Cacioppo J. Loneliness Matters: A Theoretical and Empirical Review of Consequences and Mechanisms. Ann Behav Med. 2010;40(2):218-227.

19. Holwerda TJ, Deeg D, Beekman A, et al. Feelings of loneliness, but not social isolation, predict dementia onset: Results from the Amsterdam Study of the Elderly [AMSTEL]. J Neurol Neurosurg Psychiatry. 2012;85(2):135-142.

20. Albrecht GL, Devlieger PJ. The disability paradox: high quality of life against all odds. Soc Sci Med. 1998;48(8):977-988.

21. Eccles A, Damadoran L, Harding I, Olphert W, Gilhooly M. Assistive technologies: Ethical practice, ethical research and quality of life. In: Sixsmith A, Gutman G, editors. Assistive technologies for active aging. New York: Springer; 2013:47-68.

22. Eccles A. Ethical considerations around the use of telecare technologies. Presented at: SICSA Socio-Technical Systems Conference; Apr 2010; Glasgow, University of Glasgow.

23. Eccles A. Assistive Technologies: ethical issues and policy implementation. ESRC: Making Research Count; December 5, 2012; University of Keele, UK.

24. Eccles A. The complexities of technology-based care: Telecare as perceived by care practitioners. Issues in Social Science. 2013; 1(1): $1-20$.

25. 2009 Ageing Report:Economic and budgetary projections for the EU-27 Member States (2008-2060). Available from: http://ec.europa.eu/ economy_finance/publications/publication14992_en.pdf. Accessed May $10,2014$.

26. Audit Commission. Implementing telecare. London: Audit Commission; 2004. Available from: http://archive.audit-commission.gov.uk/ auditcommission/SiteCollectionDocuments/AuditCommissionReports/ NationalStudies/Telecare.pdf. Accessed May 10, 2014

27. kingsfund.org.uk [homepage on the Internet]. Insight into the WSD programme [video presentation]. 2011. Available from: http://www. kingsfund.org.uk/audio-video/stan-newman-insight-wsd-programme. Accessed on May 10, 2014.

28. Söderlund R. The role of information and communication technology in home services: Telecare does not satisfy the needs of the elderly. Health Informatics Journal. 2004;10(2):127-137.

29. Oudshoorn N. Telecare Technologies and the Transformation of Healthcare. Basingstoke: Palgrave; 2011.

30. Magnus G. The Age of Aging. Singapore: John Wiley \& Sons; 2009.

31. Pilling D. Bending Adversity: Japan and the Art of Survival. London: Allen Lane; 2014. 
32. European Commission. Coping with an ageing population: Learning from good eHealth and telecare practices: The eCare benchmarking study. 2013. Available from: https://ec.europa.eu/digital-agenda/en/news/ ecare-benchmarking-coping-ageing-population-\%E2\%80\%93-learninggood-ehealth-and-tele-care-practices. Accessed May 10, 2014.

33. Pols J, Willems D. Innovation and evaluation: Taming and unleashing telecare technology. Sociol Health Ill. 2011;33(3):484- 498.

34. Beauchamp L, Childress AF. Principles of Biomedical Ethics. 7th ed. Oxford: Oxford University Press; 2013.

35. Wilmot S. The Ethics of Community Care. London: Cassell; 1997.

36. Factsheet: Telecare and ethics [webpage on the Internet] Care Services Improvement Partership [cited July 19, 2005]. Available from: http:// www.telecarelin.org.uk/_library/Resources/Telecare/Telecare_advice/ Factsheet-Telecare-Ethics19July2005.doc. Accessed July 13, 2014.

37. Nagel SK, Remmers H. Self-Perception and Self-Determination in Surveillance Conditions. The American Journal of Bioethics. 2012;12(9):53-55.

38. Gilligan C. In a Different Voice: Psychological Theory and Women's Development. Cambridge: Harvard University Press; 1982.

39. Noddings N. Caring: A Feminine Approach to Ethics and Moral Education. Berkeley: University of California Press; 1984.

40. Tronto J. Moral Boundaries: A Political Argument for an Ethic of Care. London: Routledge; 1994.

41. Held V. The Ethics of Care: Personal, Political, Global. New York: Oxford University Press; 2006.

42. Barnes M. Struggling for, with, and against care. Critical care: advancing an ethic of care in theory and practice; September 13, 2012; University of Brighton.

43. Barnes M. Caring and Social Justice. Basingstoke: Palgrave MacMillan; 2006.

44. Tronto J. Caring Democracy: Markets, Equality and Justice. New York: NYU Press; 2013.

45. Tao J, Drover G. Chinese and Western notions of need. Critical Social Policy. 1997;17(50):5-25.

46. Pols J, Moser I. Cold technologies versus warm care? On affective and social relations with and through care technologies. European Journal of Disability Research. 2009;3(2):159-178.

47. Greenhalgh T, Procter R, Wherton J, Sugarhood P, Shaw S. The organising vision for telehealth and telecare: discourse analysis. BMJ. 2012;2(4). pii:e001574.
48. Kamphof I. The observation of technology users using technologies. The Use of Assistive Technologies in Social Care: Addressing the Social Dimensions. Presented at: Symposium of the Scottish Universities Insight Institute; May 2013; Glasgow, University of Strathclyde.

49. Equality and Human Rights Commission [homepage on the Internet]. Close to home: An inquiry into older people and human rights in home care. 2011. Available from: http://www.equalityhumanrights.com/legaland-policy/our-legal-work/inquiries-and-assessments/inquiry-intohome-care-of-older-people/close-to-home-report. Accessed October 29, 2014.

50. Mort M, Roberts C, Callén B. Ageing with telecare: Care of coercion in austerity? Sociol Health Illn. 2013;35(6):799-812.

51. Moser I. Telecare: New values, ideals and modes of caring. Critical care: Advancing an ethic of care in theory and practice; September 14, 2012; Brighton, University of Brighton.

52. Macnish K. Unblinking eyes: the ethics of automating surveillance. Ethics Inf Technol. 2012;14(2):151-167.

53. Weinstein JM. Public Safety and Online Privacy-Myth Versus Reality. Northwestern Journal of Technology and Intellectual Property. 2013; 11(2):33-39.

54. Blaschke C, Freddolino P, Mullen E. Ageing and technology: A review of the research literature. British Journal of Social Work. 2009;39(4):641-656.

55. White D. Across the Divide: Tackling Digital Exclusion in Glasgow. Dunfermline: Carnegie UK Trust; 2013.

56. Office for National Statistics. European Comparisons of Wellbeing. London: Office for National Statistics; 2014. Accessed June 24, 2014.

57. McNeil C, Hunter J. The Generation Strain: Collective Solutions to Care in an Aging Society. London: DEMOS; 2014.

58. Bazalgette L, Salter J. Sociable Housing in Later life. London: DEMOS; 2013.

59. theguardian.com [homepage on the Internet]. Fox A. We need to learn from Germany's experiments in shared care. May 3, 2014. Available from: http://www.theguardian.com/commentisfree/2014/may/03/learngermany-experiments-shared-care. Accessed October 29, 2014.

60. Meagher G, Parton N. Modernising social work and the ethics of care. Social Work and Society. 2004;2(1):10-27.

61. Saunders P. A Nation of Homeowners. London: Routledge; 1990.
Smart Homecare Technology and TeleHealth

\section{Publish your work in this journal}

Smart Homecare Technology and TeleHealth is an international, peer-reviewed, open access online journal publishing original research, reviews, editorials and commentaries on the application of technology to support people and patients at home and in assisted living centers to optimize healthcare and management resources. Specific topics in the journal include: Development and application of

\section{Dovepress}

devices within the home and embedded in appliances; Healthcare provider communication and education tools; and drug ordering and adherence. The manuscript management system is completely online and includes a very quick and fair peer-review system, which is all easy to use. Visit http://www.dovepress.com/ testimonials.php to read real quotes from published authors. 